\title{
ABUSO DE PODER ECONÓMICO, ACAPARAMIENTO Y ESPECULACIÓN
}

\author{
ABUSE OF ECONOMIC POWER, HOARDING AND SPECULATION
}

\author{
Pierino Stucchi \\ Universidad ESAN, Perú \\ https:/ / orcid.org/0000-0001-7399-2803 \\ Fernando Ballon Estacio \\ Estudio Muñiz, Olaya, Meléndez, Castro, Ono \& Herrera Abogados, Perú \\ https:/ / orcid.org/0000-0002-5465-9391
}

\section{Resumen}

En este artículo se abordan las recientes novedades legislativas sobre los delitos de abuso de poder económico, acaparamiento y especulación en la jurisdicción peruana, así como la inconveniencia que su entrada en vigor representa para el adecuado desarrollo de las políticas de libre competencia. Se concluye que, contrariamente a lo recomendado por estándares internacionales, no se ha cumplido con las exigencias de calidad regulatoria en el contexto de una pandemia.

Palabras clave: calidad regulatoria, competencia, especulación, acaparamiento, abuso de posición de dominio, colusión, abuso de poder económico.

\begin{abstract}
This article addresses the recent legislative developments on the crimes of abuse of economic power, hoarding and speculation in the Peruvian jurisdiction, as well as the inconvenience that its validity represents for the proper development of free competition policies. It is concluded that, contrary to what is recommended by international standards, the requirements of regulatory quality have not been met in the context of a pandemic.
\end{abstract}

Keywords: regulatory quality, competition, speculation, hoarding, dominance position abuse, collusion. abuse of economic power. 


\section{Introducción: la necesidad de asegurar calidad regulatoria durante los efectos de una pandemia}

En tiempos de crisis, la preocupación y la proactividad de los agentes políticos aumenta considerablemente, pues tienen la necesidad de solucionar problemas trascendentales. Sin embargo, y precisamente a causa de dicho contexto, el riesgo de cometer errores mediante la actuación pública es mayor. Por esta razón, en la emisión de normas se deben cumplir estrictamente los principios de calidad regulatoria.

La Organización para la Cooperación y el Desarrollo Económicos (OCDE) recomienda que en tales situaciones no se deje de lado el análisis de impacto regulatorio ni la revisión constante de las medidas adoptadas, incluso cuando se requieren respuestas regulatorias céleres ${ }^{1}$. En ese sentido, no se pueden dejar de lado los elementos fundamentales de la calidad regulatoria, que consisten en: i) la identificación del problema, ii) la identificación de alternativas para solucionar el problema y iii) el análisis de las consecuencias posibles de estas alternativas con el fin de elegir aquella que solucione mejor y a menor costo el problema identificado.

Bajo estas consideraciones, se evaluará en el presente artículo, desde la perspectiva del derecho y de la política de competencia, el contenido esencial de la Ley 31040, que modifica el Código Penal y el Código de Protección y Defensa del Consumidor, adoptada por agentes políticos en el Congreso de la República del Perú.

\section{Sobre la inconveniencia de incorporar y restaurar tipos penales de manera irreflexiva}

En el Perú, dentro del contexto de crisis actual, no han sido pocos los intentos de regular las actividades económicas. Para ello, sin embargo, no se ha requerido ni convocado la participación de expertos en las materias abordadas; tampoco se ha efectuado el debido análisis del impacto regulatorio.

1 OECD, Regulatory quality and COVID-19: Managing the risks and supporting the recovery, OECD, 29 de abril de 2020, https://read.oecd-ilibrary.org/view/?ref=131_131923jisarlbai9\&title=Regulatory-Quality-and-COVID-19-Managing-the-Risk-sand-Supportingthe-Recovery 
Uno de los ejemplos más relevantes es la Ley $31040^{2}$, que, entre otros delitos, establece los siguientes: abuso de poder económico, acaparamiento, especulación.

Mediante intervenciones en el Código Penal peruano, la mencionada norma legal penal criminaliza las conductas anticompetitivas, reincorpora el delito de acaparamiento y modifica el delito de especulación.

\subsection{Abuso del poder económico}

La Ley 31040 incorpora al Código Penal el siguiente tipo penal:

\section{Artículo 232.- Abuso del poder económico}

El que abusa de su posición dominante en el mercado, o el que participa en prácticas y acuerdos restrictivos en la actividad productiva, mercantil o de servicios con el objeto de impedir, restringir o distorsionar la libre competencia, será reprimido con una pena privativa de libertad no menor de dos ni mayor de seis años, con ciento ochenta a trescientos sesenta y cinco días-multa e inhabilitación conforme al artículo $36^{\circ}$, incisos 2 y 4 .

Este nuevo delito criminaliza las principales conductas anticompetitivas ya previstas en el Decreto Legislativo 1034, Ley de Represión de Conductas Anticompetitivas (LRCA), y sancionables administrativamente: i) el abuso de posición de dominio (en adelante, APD), y ii) las conductas colusorias, tanto horizontales como verticales, que restringen la competencia.

Al respecto, no existe sustento técnico ni evidencia de que se haya analizado o de que se acredite objetivamente que el sistema administrativo de represión de conductas anticompetitivas, a cargo del Instituto Nacional de Defensa de la Competencia y de la Protección de la Propiedad Intelectual (Indecopi), no haya cumplido su finalidad preventiva, correctiva y sancionadora. Es decir, el establecimiento de este nuevo delito de abuso de poder económico no se ha visto precedido por la identificación de un problema; en consecuencia,

2 Aprobada por el Congreso de la República con fecha 5 de junio de 2020. No obstante, en ejercicio de sus atribuciones constitucionales, el Poder Ejecutivo observó este instrumento normativo. Sin embargo, el Congreso la aprobó por insistencia y la promulgó directamente con fecha 29 de agosto de 2020. 
tampoco han podido precisarse ni evaluarse alternativas para solucionar el hipotético problema que no ha sido acreditado.

Debe recordarse que en el año 2008, mediante disposiciones complementarias, la LRCA dispuso la derogación de los delitos por conductas anticompetitivas. Así, en la exposición de motivos de esta ley, se señaló como fundamento lo siguiente:

... la experiencia práctica del INDECOPI ha demostrado que la persecución administrativa - y no la persecución penal - constituye la principal forma de represión y desincentivo de prácticas anticompetitivas. A ello se añade el hecho de que el complejo análisis de los efectos anticompetitivos y la generación de eficiencias que este tipo de conductas pueden tener en el mercado, aconseja que sea un órgano técnico y administrativo el encargado de reprimirlas, sin necesidad de recurrir a sanciones más gravosas para los agentes económicos como las de tipo penal.

Sin embargo, actualmente nos encontramos de nuevo marchando en sentido contrario.

Asimismo, llama la atención que en la jurisdicción peruana se decida sancionar penalmente el APD. En general, estos casos presentan menor incidencia, como afectaciones al proceso competitivo, en comparación con los carteles (prácticas colusorias horizontales), y no tienen parámetros absolutamente definidos, ni siquiera en las principales jurisdicciones del mundo, como la Unión Europea o los Estados Unidos de América. Parece claro que las diferencias institucionales y sustantivas del APD frente a los carteles son significativas ${ }^{3}$, por lo que no resulta equitativo darles un mismo trato a través de sanciones penales.

En la experiencia peruana, incluso la persecución administrativa revela estas diferencias. Desde la entrada en vigor de la LRCA en 2008, el Indecopi ha investigado y sancionado muy pocos casos de APD. Esto se puede deber principalmente a la aplicación pragmática de un criterio de eficiencia en la utilización de los escasos recursos con los que cuenta toda agencia de competencia ${ }^{4}$, dado que:

3 Pablo Ibáñez Colomo, The shaping of EU competition law (Cambridge: Cambridge University Press, 2020).

4 OCDE, Exámenes inter-pares de la OCDE y el BID sobre el derecho y política de competencia: Perú, (OCDE, 2018), https://www.oecd.org/daf/competition/PERU-Peer-Reviews-ofCompetition-Law-and-Policy-SP-2018.pdf 
a) Es razonable que los recursos se destinen prioritariamente a las conductas que tienen un impacto negativo mucho más claro y relevante para el bienestar de los consumidores, tal como ocurre en el caso de los carteles (prácticas colusorias horizontales). Ello lleva al Indecopi, en cuanto organismo especializado que cobija a los órganos administrativos que ejercen como autoridad de defensa de la competencia, a priorizar su prevención y persecución como parte de la política de competencia en el Perú.

b) Dada la complejidad del análisis técnico y económico (por ejemplo, la delimitación del mercado relevante, la estimación del poder de mercado y de los efectos causados), así como lo ampliamente discutibles que pueden ser las circunstancias de cada caso concreto (debido a sus parámetros difusos: cuándo es abuso, cuándo está justificado y qué eficiencias deben considerarse, entre otros), el Indecopi prefiere asignar sus recursos a aquellos casos que, como los carteles, representan una mayor probabilidad de éxito en la detección, corrección y sanción.

Ello lleva a que nos encontremos actualmente en un escenario asimétrico de aplicación de la LRCA por parte del Indecopi y que, por lo tanto, no se suscite el mismo impacto disuasivo sobre las conductas consistentes en el APD que el que se genera sobre los carteles (prácticas colusorias horizontales). Pero nótese aquí que el problema es, en buena parte, el déficit de capacidades de la autoridad administrativa para el enforcement sobre un APD. Ante tal circunstancia, la imposición de sanciones, como las penas de cárcel, no aportan soluciones a dicho déficit, que podría ser aun más marcado en lo que respecta a las capacidades del Ministerio Público, titular de la acción penal. Hay que observar, igualmente, que, conforme establece la Ley 31040, la interposición de la denuncia no requiere, siquiera, de un informe favorable del Indecopi como organismo especializado en la materia.

Nos parece que una medida más racional, como alternativa que hubiera solucionado mejor y a menor costo un problema (si es que este hubiera sido identificado), podría ser el reforzamiento de políticas de responsive regulation. Como se ha señalado, el APD tiene características que dificultan la aplicación de la ley a un nivel óptimo, por lo que medidas intermedias en la pirámide regulatoria distintas de las sanciones, pero efectivas, resultarían preferibles ${ }^{5}$. Ya

5 Nader Mufdi Guerra, Responsive Regulation como estrategia de enforcement de las prohibiciones de abuso de posición dominante (Santiago de Chile: Investigaciones Centro Competencia, CeCo, 2020). 
existe un avance en este sentido, efectuado en el 2020, mediante el Decreto Legislativo 1510, que modificó la LRCA en lo referido al inicio de procedimientos sancionadores. Se entregó al fiscal administrativo la facultad de imponer medidas que restablezcan o promuevan la competencia ${ }^{6}$ en determinados casos (incluido el APD que no sea capaz de generar un efecto significativo sobre la competencia), en lugar de acusar e iniciar procedimientos administrativos sancionadores ${ }^{7}$.

A diferencia del APD, que se encuentra sujeto a la prohibición relativa que establece la LRCA, los carteles son prácticas colusorias horizontales que se hallan sujetas a la prohibición absoluta en la jurisdicción peruana. Estos son perseguidos también penalmente en distintas jurisdicciones, pues se ha considerado que, además de tener un efecto casi siempre negativo sobre el proceso competitivo y el bienestar de los consumidores, son moralmente reprochables $^{8}$. No obstante, la criminalización de los carteles puede no ser una política adecuada, sobre todo cuando, como en el caso peruano, puede distorsionar y afectar el eficaz funcionamiento del sistema correctivo y sancionador a nivel administrativo.

Cabe señalar que en Estados Unidos la política de clemencia comprende la inmunidad frente a la acción penal, a diferencia de lo que sucede ahora en

6 Al respecto, la LRCA señala:

Artículo 18.- Formas de iniciación del procedimiento

(...)

18.4. Mediante resolución debidamente motivada, la Secretaría Técnica puede, en ejercicio de una facultad discrecional, no iniciar ni instruir un procedimiento administrativo sancionador cuando determine, en función a los criterios previstos en el artículo 44 de la presente Ley, que una conducta sujeta a la prohibición relativa no esté en capacidad de tener un efecto significativo sobre la competencia. En este supuesto, la Secretaría Técnica puede imponer, de oficio o a solicitud del investigado, la implementación de acciones que restablezcan o promuevan la competencia y aseguren el cumplimiento de la Ley. La Comisión aprueba los Lineamientos para el ejercicio de esta facultad discrecional, a propuesta de la Secretaría Técnica.

7 La Secretaría Técnica de la Comisión de Defensa de la Libre Competencia, como fiscal administrativo, podrá decidir no iniciar un procedimiento sancionador, conforme a lo antes anotado. Al efecto, es importante que se generen espacios transparentes de coordinación entre esta autoridad y los investigados para la correcta aplicación de esta regla, que incluyan la oportunidad de ejercer el correspondiente derecho de defensa. Con esto se evitará destinar innecesariamente recursos a la tramitación de prolongados procedimientos que pueden no tener la eficacia esperada.

8 Osvaldo Artaza Varela, «La colusión como forma de agresión a intereses dignos de protección por el Derecho Penal: primera aproximación», Revista de Derecho 30, n. 2 (2017, diciembre): 339-366, http://revistas.uach.cl/index.php/revider/article/view /759/803 
el Perú. Así, el principal efecto negativo del nuevo delito de abuso de poder económico, establecido por la Ley 31040, es que su persecución puede perjudicar la principal herramienta de detección de carteles con la que cuentan las autoridades de defensa de la competencia: la delación compensada o el programa de clemencia. Por constituir los carteles una conducta usualmente secreta, técnicamente compleja, de evidencia fragmentada que muchas veces es destruida, la LRCA prevé, en línea con el estándar internacional, un mecanismo de incentivos que ofrece la exoneración de las sanciones aplicables a cambio de la delación del resto de participantes en un cartel y el aporte de pruebas suficientes para probar la conducta ilícita propia y de otros. Los incentivos de este programa están dirigidos a propiciar el cese de las infracciones y la colaboración con la autoridad ${ }^{9}$. La utilización de este mecanismo se ha incrementado en el Perú en los últimos años y ha permitido una mayor detección de carteles ${ }^{10}$.

Sin embargo, con la entrada en vigor de la Ley 31040, el funcionamiento del programa de clemencia que prevé la LRCA puede verse severamente afectado a nivel administrativo. Esto se debe a que podrían surgir dos escenarios en relación con las personas naturales y jurídicas involucradas en la realización de una conducta anticompetitiva.

Las personas naturales buscarían someterse a la colaboración eficaz en sede penal ante el Ministerio Público, pues el Indecopi no puede asegurarles la inmunidad criminal, y solo cooperarían con este último si obtienen primero garantías a nivel penal. No obstante, en el ordenamiento jurídico peruano, la colaboración eficaz está reservada para pocos delitos legalmente especifica$\operatorname{dos}^{11}$; así, los individuos podrían ver reducidos sus incentivos para colaborar con el Indecopi y el Ministerio Público.

Por su parte, las personas jurídicas conductoras de la actividad empresarial involucradas tendrán el incentivo de presentarse ante el programa de clemencia que administra el Indecopi, pues solo este puede garantizar la exoneración (total o parcial) de multas. Sin embargo, dado que las personas naturales que participaron en la conducta anticompetitiva ven reducidos sus

9 Cecilia O’Neill de la Fuente, «La colaboración eficaz y la libre competencia: Indecopi atrapado en el dilema del prisionero", Forseti 1, n. ${ }^{\circ} 1$ (2013): 66, https://doi.org/10.21678/forseti. v1i1.1193

10 OCDE, Exámenes inter-pares de la OCDE y el BID.

11 Asociación ilícita, terrorismo, lavado de activos, criminalidad organizada, concusión y corrupción de funcionarios, entre otros que establezca la ley. 
incentivos para colaborar, sin su ayuda, la recolección de información y pruebas suficientes para obtener clemencia se verá bastante dificultada. En ese caso, podría resultar menos riesgoso o costoso - para las personas naturales que desarrollaron la conducta desde la empresa- esperar a que el Indecopi inicie una investigación por cuenta propia, dificultándose, de esta manera, la detección temprana de carteles.

Por tanto, la existencia de sanciones penales — que podrían presumirse más severas- no se traducen necesariamente en más casos detectados ni en una mayor eficacia para disuadir a otros de practicar acciones anticompetitivas, en particular las conductas colusorias que asumen la forma de carteles. En ese sentido, desde la OCDE, por ejemplo, se señala que, para lograr una óptima disuasión de carteles, debería estar garantizado el «efecto dual» de la delación compensada. Es decir, que pueda comprender tanto la sanción administrativa como la pena de cárcel ${ }^{12}$.

Además, el nuevo delito de abuso de poder económico enfrentará desde su propia aplicación amplias discusiones vinculadas al principio non bis in ídem frente a la tramitación de un procedimiento administrativo sancionador y un proceso penal contra una misma persona que sea imputada por realizar una conducta anticompetitiva (infracción) y cometer abuso de poder económico (delito), en mérito a los mismos hechos.

Asimismo, cuando en un proceso penal se discutan hechos que resulten igualmente relevantes para la resolución de un procedimiento administrativo en materia de conductas anticompetitivas, será necesario contextualizar y aplicar tanto la regla de la prevalencia penal (también conocida como prejudicialidad penal) como la de la vinculación de la Administración respecto de los hechos probados judicialmente. Esto conforme a lo establecido por la Ley Orgánica del Poder Judicial y el Código Procesal Penal.

En suma, la persecución del nuevo delito de abuso de poder económico podría provocar mayor discusión, menos claridad, menos celeridad y, probablemente, menos eficacia en la disuasión, corrección y sanción de conductas anticompetitivas. ¿Cuál de las siguientes opciones resulta un mayor desincentivo para una persona natural: una pena privativa de libertad de cuatro

12 OECD, Criminalisation of cartels and bid rigging conspiracies: a focus on custodial sentences, Working Party n. ${ }^{\circ} 3$ on Co-operation and Enforcement, OECD, 9 de junio de 2020, https:// one.oecd.org/document/DAF/COMP/WP3(2020)1/en/pdf 
años suspendida o una multa administrativa que puede superar los cien mil dólares estadounidenses?

En cuanto a las garantías para los administrados y su presunción de inocencia, debemos anotar la posibilidad de que el Ministerio Público, antes de actuar, decida esperar a que el Indecopi concluya el trámite del procedimiento administrativo que haya iniciado con el fin de comprobar la realización de conductas anticompetitivas. En tal caso, sin embargo, nos hallaremos ante un potencial deterioro del derecho constitucional a la presunción de inocencia, con el consiguiente impacto en el ámbito penal; y es que cualquier decisión de la autoridad administrativa que se fundamente en un estándar probatorio menor que el penal — que es el utilizado por el Indecopi indebidamente en diferentes decisiones ${ }^{13}$ — puede condicionar el análisis de la Fiscalía y del juez penal. ¿Y si el juez considera no probados determinados hechos o conductas que el Indecopi sí consideró probados? El procedimiento sancionador a cargo de este último podría quedar sin fundamento probatorio y devenir en nulo o infundado.

En consecuencia, de mantenerse en el ordenamiento jurídico peruano el delito de abuso de poder económico, debería establecerse alguna regla, con rango de ley, que determine que el programa de clemencia ante el Indecopi comprende inmunidad también frente a la acción penal; a ella habría que sumarle otra norma que disponga lo siguiente para que proceda la denuncia penal:

i) La declaración de una infracción administrativa, en sede del Indecopi, y la correspondiente sanción por una conducta anticompetitiva deben encontrarse firmes.

ii) En dicha declaración la autoridad administrativa debe haberse inhibido de sancionar a la persona natural involucrada directamente en la realización de tal conducta.

13 La Comisión de Defensa de la Libre Competencia ya ha tomado una (indebida) posición (que debe ser corregida) sobre este tema, reconociendo que el estándar probatorio que utiliza para resolver sus casos es más relajado que el utilizado en materia penal:

43. Sin perjuicio de ello, cabe señalar que, tratándose de infracciones de índole administrativa, los procedimientos en materia de defensa de la libre competencia se caracterizan por un estándar de prueba menos rígido que el aplicable en los procesos penales, formal y materialmente más elevado, debido a la gravedad de las penas que se pueden aplicar a quienes resulten responsables. (Resolución 030-2018/CLC-INDECOPI del 14 de mayo de 2018, https:/ / servicio.indecopi.gob.pe/buscadorResoluciones/getDoc?docID=workspace:/ / SpacesStore/8674348c-f4d7-46ae-a60b-a2f7935b9c00) 
iii) En el acto mediante el cual se concrete tal decisión se debe solicitar al Ministerio Público la evaluación de la correspondiente denuncia penal. Sumado a ello, se necesita que el Indecopi, en su actuación procedimental, corrija su actual estándar probatorio y aplique, para la determinación de conductas anticompetitivas, el estándar de prueba más allá de toda duda razonable (beyond a reasonable doubt), con la finalidad de vencer la presunción de inocencia, que corresponde a toda persona por mandato constitucional, lo cual es claramente entendido por doctrina autorizada ${ }^{14}{ }^{15}$; asimismo, se debe prever, mediante norma con rango de ley, que la prescripción del reproche penal que implica el delito de abuso de poder económico se interrumpe cuando el fiscal administrativo (Secretaría Técnica-Dirección) notifica a una persona natural que la tiene comprendida en una investigación preliminar que, luego, podría tener consecuencias penales para ella, en mérito de la configuración del delito de abuso de poder económico.

\title{
2.2 Acaparamiento
}

La Ley 31040 restituye el delito de acaparamiento, que había sido derogado expresamente por la LRCA en el año 2008 por considerarlo inconstitucional ${ }^{16}$ :

\begin{abstract}
Artículo 233.- Acaparamiento
El que provoca escasez o desabastecimiento de bienes y servicios esenciales para la vida y la salud de las personas, mediante la sustracción o acaparamiento, con la finalidad de alterar los precios habituales en su beneficio, y con perjuicio de los consumidores, será reprimido con pena privativa de libertad no menor de cuatro ni mayor de seis años y con ciento ochenta a trescientos sesenta y cinco días-multa.
\end{abstract}

14 Informe jurídico privado de José Laguna de Paz, 2021. Dictamen jurídico sobre el estándar de prueba exigible en los procedimientos administrativos sancionadores en materia de defensa de la competencia, con particular referencia a la culpabilidad del infractor. Elaborado a propósito del procedimiento tramitado mediante Expediente 001-2020/CLC ante la Comisión de Defensa de la Libre Competencia del Indecopi.

15 Informe jurídico privado de Alejandro Huergo, 2021. Dictamen sobre el estándar probatorio y su alcance en procedimiento sancionador de competencia.

16 En relación con esta derogación, la exposición de motivos de la LRCA precisó que:

... [se] despenaliza la figura conocida como "acaparamiento" prevista en el artículo 233 del Código Penal, puesto que su tipificación producida en 1991 contraviene el sistema económico de economía social de mercado previsto en la Constitución Política del Perú de 1993, así como el principio rector de la libre competencia reconocido en el artículo 61 de la carta magna. Actualmente vamos, nuevamente, en sentido contrario. 
Debe notarse que un acaparamiento que tuviera capacidad real de incrementar precios en el mercado solamente podría ser realizado por una empresa con posición de dominio, de modo que el clásico modelo de monopolio se aplique: reducir la cantidad ofertada para incrementar precios. No sucede así con las empresas que no tienen tal posición. Este tipo penal debió haber previsto el elemento de dominancia para evitar investigaciones sobre conductas no lesivas y condenas erróneas.

Pero aun cuando este elemento hubiera sido incluido, evaluados los elementos del tipo, se trata de una figura cuya determinación corre un alto riesgo de devenir en arbitraria; asimismo, su definición en cada caso concreto resulta gaseosa, pues «acaparar» o «sustraer del comercio» equivale exactamente a dosificar el stock para asegurar un abastecimiento racional (por ejemplo, frente a una demanda desmesurada y especulativa); o, también, a tomar decisiones estratégicas de compra y venta según una propia y legítima política comercial.

De igual modo, si un productor que no es dominante sino un tomador de precios prevé que los precios de su producto van a incrementarse, ¿tendría que deshacerse de toda su producción de inmediato o esperar a que los precios suban para colocar su producción? ¿El productor estará acaparando (reteniendo recursos productivos) si decide producir a una velocidad menor que la de una demanda que se incrementa apresuradamente?

Ahora, si bien la disposición complementaria final única señala que la lista de bienes esenciales será establecida por la autoridad competente, con el fin de evitar una ley penal «en blanco ${ }^{17}$, varios elementos continúan siendo de difícil interpretación. El concepto de «precio habitual», por ejemplo, resulta, de por sí, muy difícil de determinar: dependiendo del sector y del mercado relevante particular, los precios pueden cambiar diariamente, semanalmente o sobre la base de algún otro periodo de tiempo. Basta tan solo observar los precios al por mayor de los productos agrícolas, sin duda esenciales para la vida de las personas y las familias. En este contexto, cabría preguntarse: ¿qué se entiende por «precio habitual»?, ¿acaso se trata del precio promedio? Y si fuera así, ¿qué periodo se debe tomar como referencia? Por otra parte, este nuevo tipo penal se instaura de manera genérica y no bajo una situación de emergencia, lo cual implica un control de precios permanente en la jurisdic-

17 Joan Manuel Álvarez Porras, «El delito de acaparamiento en el Perú», Gaceta Penal y Procesal Penal 139 (2021, enero): 101. 
ción peruana, algo que solo llevaría a incrementar la escasez de los productos que más requiere la sociedad.

Considerando una figura tan gaseosa y de tan arbitraria determinación, carente de una norma extrapenal que le brinde certeza, su criminalización con las graves consecuencias que esto involucra- genera desincentivos muy fuertes para la producción o comercialización de aquellos productos esenciales cuyo abastecimiento se pretende asegurar. Es decir, la criminalización promueve, contrariamente a lo que se desea, escasez en el mercado formal y expansión de mercados ilegales.

\subsection{Especulación}

De otro lado, la Ley 31040 modifica la tipificación del delito de especulación:

\section{Artículo 234.- Especulación y alteración de pesos y medidas}

El productor, fabricante, proveedor o comerciante que incrementa los precios de bienes y servicios habituales, que son esenciales para la vida o salud de la persona, utilizando prácticas ilícitas que no se sustente (sic) en una real estructura de costos y el correcto funcionamiento del mercado, aprovechando una situación de mayor demanda por causas de emergencia, conmoción o calamidad pública será reprimido con pena privativa de libertad no menor de dos ni mayor de seis años y con ciento ochenta a trescientos sesenta y cinco días-multa.

Si la especulación se comete durante un estado de emergencia, declarado por el Presidente de la República, la pena privativa de la libertad será no menor de cuatro ni mayor de ocho años y con ciento ochenta a trescientos sesenta y cinco días-multa.

Como se ha señalado antes, el concepto de «precio habitual» es muy difícil de determinar, pues, dependiendo del sector y del mercado relevante particular, los precios difieren según el nivel comercial o las particularidades de cada agente económico; pueden, asimismo, cambiar todos los días, semanalmente o sobre la base de algún otro periodo. A manera de ejemplo, se puede mencionar el caso de los productos agrícolas (presumiblemente candidatos para ser declarados esenciales): existen miles de productores, cada uno con sus propias circunstancias, estructuras de costos y precios; y se debe tener en cuenta, además, a otros miembros y factores de la cadena de comercialización: acopiadores, transportistas, mayoristas, mercados de abastos principales, mercados 
de abastos secundarios, canal moderno (supermercados), minimarkets, bodegas, distribuidores independientes (delivery), etcétera.

En relación con tales productos, los precios cambian de manera diaria o semanal. Si se observa con más detalle el comercio minorista (o retail), las cadenas de tiendas de conveniencia, las bodegas o los supermercados, entre otros, se encontrará que cada uno de ellos tiene una política de ajuste de precios diferente, un «precio habitual» que se ha movido a lo largo de días, semanas, meses o años. Teniendo en cuenta ese contexto, cabe preguntarse nuevamente: ¿qué es el «precio habitual»? ¿Acaso el precio promedio? ¿De qué periodo? Ciertamente, la determinación del precio habitual resultará, inevitablemente, arbitraria.

Lo más preocupante, sin embargo, se halla en relación con la asunción de que el incremento de precios frente a una situación de alta demanda es per se ilegal. Este tipo penal presume que, en situaciones de emergencia o calamidad, es deber de los productores o comerciantes mantener sus «precios habituales», a pesar de que es natural que condiciones anormales generen las consiguientes alteraciones sobre los riesgos, los costos y las rentabilidades, que se traducen en cambios o aumentos de precios. En suma, la obligación implícita de mantener precios que impone este tipo penal es también un control de precios, que solo contribuiría a incrementar la escasez de los productos que más requiere la sociedad en una situación crítica.

El tipo penal de especulación plantea que los cambios en la estructura de costos pueden justificar el incremento de precios; dicha recomposición, sin embargo, requiere asunciones, metodologías y reglas de imputación que podrían ser distintas de las utilizadas por la autoridad penal. En ese caso, existe un riesgo grave de que un agente económico que incrementa sus precios de acuerdo con sus propios cálculos esté cometiendo un delito si la autoridad aplica cálculos distintos.

Esta tipificación penal genera un elevado grado de incertidumbre y, como consecuencia de ello, un gran desincentivo para producir o comercializar los productos esenciales regulados. Nuevamente, la criminalización genera escasez en el mercado formal y expansión del mercado ilegal en una situación sumamente crítica como lo es una emergencia, conmoción o calamidad pública. Nos encontramos una vez más frente a un tipo penal en blanco que carece de una norma extrapenal que le brinde certeza.

Además, la implementación de controles de precios elimina los incentivos que generan los precios altos temporales para ampliar la oferta. Esto se 
ha observado durante la pandemia con implementos tales como mascarillas, equipos de protección, mandiles, alcohol, productos de limpieza, etc., cuyos incrementos iniciales de precios ocasionaron que muchas empresas se orienten a atender la demanda insatisfecha, con lo cual los precios retornaron hacia niveles regulares.

\section{Conclusión}

En general, los tres delitos analizados, establecidos por la Ley 31040, no han sido objeto de una debida evaluación y reflexión durante el proceso legislativo en la jurisdicción peruana. Por esta razón, y debido a que no se ha seguido una metodología que garantice la calidad regulatoria, generan efectos que no contribuyen con una adecuada política de competencia en el país.

\section{REFERENCIAS}

Álvarez Porras, Joan Manuel. «El delito de acaparamiento en el Perú». Gaceta Penal y Procesal Penal 139 (2021, enero): 95-107.

Artaza Varela, Osvaldo. «La colusión como forma de agresión a intereses dignos de protección por el Derecho Penal: primera aproximación». Revista de Derecho 30, n. ${ }^{\circ}$ 2 (2017, diciembre): 339-366. http://revistas.uach.cl/index.php/revider/article/ view $/ 759 / 803$

Ibáñez Colomo, Pablo. The shaping of EU competition law. Cambridge: Cambridge University Press, 2020.

Mufdi Guerra, Nader. Responsive Regulation como estrategia de enforcement de las prohibiciones de abuso de posición dominante. Santiago de Chile: Investigaciones Centro Competencia (CeCo), 2020. https:/ / centrocompetencia.com/wp-content/ uploads/2020/02/Nader-Mufdi.-Responsive-Regulation-como-estrategia-deenforcement-de-las-prohibiciones-de-APD.pdf 
OCDE. Exámenes inter-pares de la OCDE y el BID sobre el derecho y politica de competencia: Perú. OCDE, 2018. https://www.oecd.org/daf/competition/PERU-PeerReviews-of-Competition-Law-and-Policy-SP-2018.pdf

OECD. Regulatory quality and COVID-19: Managing the risks and supporting the recovery. OECD, 29 de abril de 2020. https: / / read.oecd-ilibrary.org/view / ?ref=131_131923jisarlbai9\&title=Regulatory-Quality-and-COVID-19-Managing-the-Risk-sandSupporting-the-Recovery

OECD. Criminalisation of cartels and bid rigging conspiracies: a focus on custodial sentences. Working Party n. ${ }^{\circ} 3$ on Co-operation and Enforcement. OECD, 9 de junio de 2020. https://one.oecd.org/document/DAF/COMP/WP3(2020)1/en/pdf

O’Neill de la Fuente, Cecilia. «La colaboración eficaz y la libre competencia: Indecopi atrapado en el dilema del prisionero». Forseti 1, n. ${ }^{\circ} 1$ (2013): 30-91. https://doi. org/10.21678/forseti.v1i1.1193

\section{Sobre el autores}

\section{Pierino Stucchi}

Director de la Facultad de Derecho y Ciencias Sociales de la Universidad ESAN. Socio principal del Estudio Muñiz, Olaya, Meléndez, Castro, Ono \& Herrera Abogados. Considerado como leading individual en su especialidad por The Legal 500 (ranking inglés de abogados). Presidente de la Sociedad de Derecho y Empresas Digitales (Sodital). Exfuncionario internacional de la Comunidad Andina de Naciones (CAN). Exgerente legal del Instituto Nacional de Defensa de la Competencia y de la Protección de la Propiedad Intelectual (Indecopi).

\section{Fernando Ballon Estacio}

Abogado. Egresado de la Maestría en Derecho de la Empresa de la Universidad Nacional Mayor de San Marcos. Diplomado de Postítulo en Derecho y Política de la Competencia por la Universidad de Chile. Miembro del Instituto de Competencia y Regulación (ICR). Asociado en el Estudio Muñiz, Olaya, Meléndez, Castro, Ono \& Herrera Abogados. 